\title{
A REDUÇÃO DO GERÚNDIO NO ATLAS LINGUÍSTICO DO PARÁ: UMA ABORDAGEM VARIACIONISTA
}

\author{
Aluiza Alves de Araújo (UECE) \\ Maria do Socorro Silva de Aragão (UFC) \\ Brenda Kathellen Melo de Almeida (UECE)
}

Resumo: Embasado na Sociolinguística Variacionista, este trabalho investiga a realização do fonema oclusivo /d/ no morfema "ndo" em verbos conjugados no gerúndio. Nosso corpus é constituído por 40 informantes provenientes do ALiSPA (Atlas Linguístico Sonoro do Pará), pertencentes a ambos os sexos/gêneros e a duas faixas etárias: de 19-33 e 40-70 anos. Todos possuem instrução até o 50 ano do ensino fundamental. A fim de descobrirmos como se dá a interferência de fatores sociais sobre a realização do fonema, controlamos as seguintes variáveis: sexo/gênero, faixa etária e área geográfica. Os resultados mostraram que os homens, os mais jovens e os informantes provenientes das cidades de Itaituba e Conceição do Araguaia tiveram uma maior produção do apagamento da oclusiva /d/.

Palavras-Chave: Redução do gerúndio; Atlas Linguístico Sonoro do Pará; Sociolinguística Variacionista.

Abstract: Grounded in Variationist Sociolinguistics, this paper investigates the performance of / d/ occlusive phoneme in gerund morpheme "ndo". Our corpus consists of 40 informants from the ALiSPA (Linguistic Atlas Sound of Pará), belonging to both sexs/genders and two age groups: $19-33$ and $40-70$ years old. All have education up to the 5 th grade of elementary school. In order to find out what the interference of social factors on the realization of the phoneme is like, the following variables have been controlled: sex/gender, age and geographical area. The results showed that men, younger people (19-33 years old) and the informants from the towns of Itaituba and Conceição do Araguaia had a higher production of deletion of the /d/ occlusive.

Keywords: Reduction of the gerund; Sound Linguistic Atlas of Pará; Variationist Sociolinguistics. 


\section{INTRODUÇÃO}

Com base nos pressupostos da Sociolinguística Variacionista (WEINREICH; LABOV; HERZOG, 2006 [1968]; LABOV, 1972), este estudo investiga a supressão do fonema oclusivo dental /d/ no morfema "ndo", especificamente em verbos conjugados no gerúndio, como em fervendo, que admite duas possibilidades: a presença da dental alveolar, pronunciada no final da palavra (fervendo), e a ausência, quando o fonema é suprimido (ferveno). Assim, para sabermos quais variáveis extralinguísticas atuam no falar paraense sobre este fenômeno, controlamos os seguintes fatores: sexo/gênero, faixa etária e área geográfica. Não analisamos os fatores de natureza linguística, porque eles, com certeza, sofreriam interferência de natureza lexical.

De acordo com Martins (2004), o fenômeno em questão consiste no resultado da assimilação do fonema dental alveolar /d/ pelo fonema nasal dental /n/ nos contextos em que ocorre o grupo "ndo"; melhor dizendo, há uma assimilação de /d/ pelo /n/, só então ocorre o apagamento, assim ilustrado: $n d->-n n->-n-$.

Mollica e Mattos (1989) afirmam que a variante reduzida é comum às línguas de origem latina em seu estágio atual. Ou seja, a assimilação não é um fenômeno 
exclusivo do português brasileiro e ocorre em outras línguas, como os dialetos crioulos e o espanhol. Entretanto, mesmo pertencendo à outras línguas, o fenômeno em questão é visto com estigma, o que fica evidenciado nas palavras de Coutinho (1976, p.326) que, referindose à redução do gerúndio, assevera: "essas formas profundamente alteradas, esse vocabulário comum e rústico, essa construção viciadíssima, que caracterizam o falar do nosso roceiro". Essa avaliação preconceituosa do autor é amplamente refutada pelos estudiosos da Sociolinguística Variacionista, pois, conforme Vieira (2011, p.10), "o apagamento da oclusiva dental /d/ não pode ser considerado um vulgarismo ou marca de um falar roceiro, mas um índice da instabilidade e da heterogeneidade do sistema linguístico, condicionada por fatores sociais".

O corpus utilizado nessa pesquisa pertence ao ALiSPA (Atlas Linguístico Sonoro do Pará), do qual utilizamos as cartas fonéticas "andando", "sorrindo" e "fervendo". Os 40 informantes do ALiSPA possuem até o 5o ano do ensino fundamental, pertencem a ambos os sexos/gêneros e estão estratificados em duas faixas etárias (I- de 19 a 33 anos; II- de 40 a 70 anos). Adotamos nessa pesquisa a mesma estratificação da faixa etária encontrada no ALiSPA. 
O ensino da língua pressupõe o conhecimento da realidade linguística dos falantes e, como o fenômeno analisado é muito presente em diversas variedades linguísticas do Brasil, este estudo também contribuirá para a descrição da variedade linguística falada no Pará, já que apresentaremos uma fotografia sociolinguística do fenômeno nesta região.

Para tanto, dividiremos este artigo em cinco partes principais: a primeira é essa introdução, que apresenta o objeto de estudo, o objetivo da pesquisa e sua relevância; a segunda aborda os estudos variacionistas a respeito da redução do gerúndio no português do Brasil; a terceira traz a metodologia, apresentando o corpus utilizado, o perfil dos informantes e os procedimentos utilizados na coleta de dados; a quarta trata dos resultados obtidos; a quinta parte traz nossas considerações finais.

\section{ESTUDOS VARIACIONISTAS SOBRE A REDUÇÃO DO GERÚNDIO NO PORTUGUÊS BRASILEIRO}

Nesta seção, apresentamos, brevemente, em ordem cronológica, alguns dos estudos mais atuais - Ferreira (2010); Martins e Bueno (2011); Vieira (2011); Brasileiro; Castro (2013) - que tratam, no português brasileiro, do fenômeno em pauta, sob a perspectiva variacionista, destacando, em 
cada trabalho, os resultados dos fatores extralinguísticos, já que serão esses os que examinaremos nessa pesquisa.

Ferreira (2010) analisou, no dialeto de São José do Rio Preto - SP, o apagamento de /d/ no morfema de gerúndio. $\mathrm{O}$ estudo contempla outras perspectivas de análise, mas neste espaço nos deteremos apenas a abordagem variacionista. A amostra foi constituída por 76 entrevistas de narrativa de experiência provenientes do banco de dados Iboruna ${ }^{1}$. Os informantes são de ambos os sexos/gêneros e possuem renda até 10 salários mínimos. Foram examinadas, além das variáveis extralinguísticas (faixa etária: 7 a 15 anos, 16 a 25 anos, 26 a 35 anos, 36 a 55 anos e mais de 55 anos; escolaridade: ensino fundamental 1, ensino fundamental 2, ensino médio e ensino superior; e sexo/gênero: masculino e feminino, três variáveis linguísticas, a saber: estrutura sintática, material interveniente entre o auxiliar e o verbo no gerúndio da perífrase e tipo de auxiliar em perífrases.

Das 999 ocorrências de gerúndio na amostra, 72\% apresentaram o apagamento, evidenciando que os falantes produzem mais a forma não-padrão. As variáveis selecionadas como relevantes para o fenômeno foram: sexo/gênero (homens, com peso relativo 0,59 ), escolaridade, (o 10 ciclo

1 Trata-se de um banco de dados de amostra de fala da região Noroeste do Estado de São Paulo, constituído no período de 2004 a 2007 e que reúne 162 amostras de fala. 
do ensino fundamental, com peso 0,72), faixa etária (26 a 35 anos, com peso 0,64$)$ e contexto morfossintático (justaposição, com peso 0,80 ). O estudo também revelou que a aplicação do apagamento passa a ser menos produtiva a partir da faixa etária de 36 a 55 anos.

Martins e Bueno (2011) investigaram a redução do gerúndio em duas cidades do Mato Grosso do Sul: Dourados e Ponta Porã. O corpus da pesquisa foi constituído por 12 informantes, homens e mulheres, analfabetos e alfabetizados até o ensino fundamental, pertencentes às seguintes faixas etárias: de 20 a 50 anos e acima de 50 anos. Os resultados revelaram que, de um total de 104 ocorrências, 53,84\% pertencem à forma reduzida. Em relação ao grupo sexo/gênero do informante, as mulheres foram as que mais utilizaram a redução $(82,5 \%)$ e, quanto à faixa etária, o estudo mostrou que os indivíduos mais jovens, de 20 a 50 anos, são os que mais produziram a variante inovadora (53\%). Em relação à escolaridade, os alfabetizados tiveram um índice menor de redução, com $34,2 \%$ das ocorrências.

Vieira (2011) abordou a supressão de /d/ no morfema de gerúndio, na cidade de Taboco - MS, com base em uma amostra constituída por 16 informantes, 8 mulheres e 8 homens com escolaridade até o 9o ano do ensino 
fundamental, distribuídos em duas faixas etárias (faixa 1: 15 a 35 anos; e faixa 2: acima de 50 anos). Para a obtenção dos dados, foi utilizada a entrevista semiestruturada (entrevista com um roteiro prévio, mas não restrita ao mesmo). Além das variáveis sexo/gênero e faixa etária, foram controlados os seguintes grupos de fatores: classe morfológica, extensão do vocábulo, contexto precedente e contexto seguinte.

Os dados foram submetidos à análise do programa computacional GoldVarb X e revelaram que o percentual de apagamento é de 79,58\%. As variáveis favorecedoras da regra são: a extensão do vocábulo (trissílabos, 94\% e polissílabos, 93\%); o contexto precedente com vogal (baixa, 68\%; vogal média ê e é, $88 \%$ e vogal anterior alta i, 92\%); o contexto seguinte (bilabial nasal, 92\%; alveolares, $84 \%$; oclusivas bilabiais, $83 \%$; oclusivas velares, $80 \%$; fricativas labiodentais, 82\%; oclusiva dental, 74\%; as vogais posteriores, $88 \%$, e central, $80 \%$; e a pausa, $82 \%$ ). Já, em relação ao sexo/gênero, os homens (80\%) demonstram uma maior tendência ao apagamento do que as mulheres (70\%). Todos os resultados obtidos na pesquisa foram dados em porcentagens e não em pesos relativos.

Brasileiro e Castro (2013) investigaram vários fenômenos linguísticos, dentre eles a redução do gerúndio, na cidade 
baiana de Santo Antônio de Jesus. O corpus foi constituído por 8 informantes, de ambos os sexos, estratificados em duas faixas (20-40 e 50-70 anos) e com ensino médio completo. 0 estudo também considerou as áreas urbana e rural. Ficou constatado que o fenômeno foi recorrente em ambas as áreas e em todos os vocábulos no gerúndio ocorreu a queda da oclusiva dental. É importante ressaltar que o estudo verifica apenas a ocorrência (ou não ocorrência) dos fenômenos pesquisados, considerando as variáveis já mencionadas.

Os trabalhos examinados aqui mostram que o apagamento de /d/ no morfema de gerúndio predomina sobre a sua manutenção. Vimos também que a redução ocorre tanto em áreas urbanas quanto rurais (BRASILEIRO; CASTRO, 2013). Com relação à variável sexo/gênero, os homens tendem a favorecer o apagamento, diferentemente das mulheres (FERREIRA, 2010; VIEIRA, 2011). No tocante à escolaridade, quanto menor a escolaridade, maior a frequência de uso da redução (FERREIRA, 2010; MARTINS; BUENO, 2013). No que se refere à faixa etária, os mais jovens favorecem mais o emprego da forma reduzida (FERREIRA, 2010; MARTINS; BUENO, 2013).

\section{METODOLOGIA}

O Atlas Linguístico Sonoro do Pará (ALiSPA) resulta de um projeto coordenado pelo professor Dr. Abdelhak Razky, 
vinculado ao curso de Letras da Universidade Estadual do Pará, e que teve início no ano de 1996, tendo sido finalizado em 2004, com a sua publicação. ${ }^{2}$

Para a elaboração do atlas, foi adotado o Questionário Fonético-Fonológico, elaborado pelo comitê do projeto do Atlas Linguístico do Brasil (ALiB), que é composto por 159 perguntas com a finalidade de verificar variações fonéticas no espaço social e no tempo. A aplicação dos questionários aconteceu no período de 2000 e 2001.

O processo de coleta dos dados se deu com a escolha de 4 informantes em cada localidade, 2 homens e 2 mulheres. As faixas etárias são as seguintes: 2 informantes entre 19 e 33 anos e 2 informantes entre 40 e 70 anos. Todos os entrevistados possuem até o 5으 ano do ensino fundamental. Para a pesquisa em questão, utilizamos as respostas de todos os 40 informantes do ALiSPA.

A escolha das dez localidades (Breves, Belém, Bragança, Cametá, Abaetetuba, Itaituba, Altamira, Marabá, Santarém e Conceição do Araguaia) que foram contempladas pelo ALiSPA seguiu critérios históricos, sociais e econômicos.

Nosso trabalho consistiu, primeiramente, em fazer o levantamento de todas as cartas que continham itens lexicais no gerúndio. O atlas possui apenas três, a saber: andando

2 Disponível em http://www.ufpa.br/alipa/. Acesso em: 26.Jun.2015. 
(carta 94), sorrindo (carta 106) e fervendo (carta 136). Foram transcritas 113 ocorrências, que posteriormente foram codificadas, digitadas e submetidas à análise estatística do programa computacional GoldVarb X (SANKOFF; TAGLIAMONTE; SMITH, 2005).

Não controlamos variáveis linguísticas neste estudo, pois, caso isso fosse feito, nossos resultados seriam, com certeza, deturpados pela influência do item lexical. Assim, decidimos analisar somente as variáveis extralinguísticas, que foram: o sexo, a faixa etária e a área geográfica do informante. A seguir, apresentamos brevemente cada um dos grupos de fatores testados aqui.

a) Sexo

Vieira (2011) mostrou que as mulheres utilizam mais a manutenção de /d/ no morfema de gerúndio, que é a forma mais conservadora e padrão, já os homens mostraram preferência pela forma reduzida, a variante inovadora e não padrão. A fim de investigar se os homens aplicam mais a forma não padrão do que as mulheres, analisamos o comportamento linguístico de ambos.

b) Faixa etária

Na pesquisa de Martins e Bueno (2011), a supressão da oclusiva dental no grupo "ndo" é maior entre os informantes 
da faixa etária de 20 a 50 anos, enquanto aqueles acima de 50 anos tendem a preservar a dental. A interpretação das autoras é que "as pessoas mais velhas são mais conservadoras em sua forma de falar, têm um cuidado maior ao se comunicar, dando preferência à forma de prestígio" (MARTINS; BUENO, 2011, p.19). Para averiguar se os mais jovens usam mais a variante inovadora na amostra examinada, controlamos a variável faixa etária: faixa 1, entre 19 a 33 anos e faixa 2, entre 40 e 70 anos.

c) Área Geográfica

Segundo Santana (2012, p.62), “A variável diatópica (e suas implicações de ordem social, econômica e cultural) influencia a variação linguística e pode ser considerada como um dos diversos fatores que atuam na mudança de uma língua". Por isso, controlamos as localidades pertencentes ao ALiSPA neste estudo, embora nenhum outro que tenha abordado este tema controlou esta variável. Seguem as localidades analisadas aqui: Santarém, Breves, Belém, Bragança, Cametá, Abaetetuba, Itaituba, Altamira, Marabá e Conceição do Araguaia.

\section{ANÁLISE DOS RESULTADOS}

Nesta seção, apresentaremos os resultados percentuais obtidos para as variantes analisadas e para cada grupo de 
fatores testado nesta pesquisa, interpretando o que os dados nos indicam, com base na literatura sociolinguística.

Gráfico 1 - Frequências de uso das variantes no ALiSPA

De um total de 113 dados, a realização da dental no gerúndio obteve 101 (89,4\%) ocorrências e apenas 12 (10,6\%) sofreram a redução do gerúndio como mostra o gráfico 1 . É bom lembrar que as frequências encontradas aqui se referem a dados extraídos do Questionário Fonético, que envolve certo grau de tensão, pois o informante, neste tipo de entrevista, responde a perguntas previamente elaboradas e, na grande maioria das vezes, faz isso apenas com uma única palavra. Além disso, o informante não conhece o entrevistador, o que reduz o nível de espontaneidade na fala. Portanto, o tipo de questionário aplicado aos informantes pode explicar por que a redução de gerúndio ocorre com uma frequência de uso tão baixa, quando comparamos com outros estudos (FERREIRA, 2010; VIEIRA, 2011; MARTINS; BUENO, 2011), que apresentaram o uso predominante da variante apagamento.

Encontramos, na primeira análise estatística, nocautes ${ }^{3}$ no grupo área geográfica, pois as localidades Abaetetuba, Belém, Breves e Cametá mantiveram a dental de forma categórica. Para retirarmos estes fatores de efeito categórico, realizamos

3 "[...] é um fator que, num dado momento da análise, corresponde a uma frequência de $0 \%$ ou $100 \%$ para um dos valores da variável dependente" (GUY; ZILLES, 2007, p.158). 
mais uma rodada com o programa GoldVarb X (SANKOFF; TAGLIAMONTE; SMITH, 2005), desprezando os nocautes, mas mantendo todas as ocorrências, já que tínhamos um reduzido número de dados na amostra. Os nocautes foram excluídos porque nosso interesse era estudar apenas os dados em variação.

Na segunda análise estatística, sem a presença dos nocautes, o programa não selecionou nenhuma variável relevante. Acreditamos que isso tenha ocorrido devido ao pequeno número de dados obtidos. Por esse motivo, apresentaremos, a seguir, a análise dos fatores controlados com base, exclusivamente, nas frequências obtidas para cada um, pois os pesos relativos não puderam ser gerados.

a) Faixa etária

Conforme Tarallo (2001), o controle da faixa etária do informante seria relevante para descobrirmos se o fenômeno linguístico em questão estaria estabilizado (quando a idade do informante não exerce influência) ou numa mudança em progresso (quando a aplicação do fenômeno é maior entre os jovens e menor entre os mais velhos).

\begin{tabular}{llll}
\hline \multicolumn{1}{l}{ Fatores } & \multicolumn{1}{l}{ Aplica/Total } & $\%$ \\
\hline \multicolumn{1}{l}{ Faixa I (19 a 33 anos) } & 9/59 & 15,3 \\
\hline Faixa II (40 a 70 anos) & $3 / 54$ & 5,6 \\
\hline
\end{tabular}

Tabela 1 - Frequências da faixa etária sobre a supressão de /d/ no morfema "ndo" 
Como podemos observar na tabela 1 , os dados mostram que a redução do gerúndio ocorreu com mais frequência entre os informantes pertencentes à faixa etária mais jovem $(15,3 \%)$, que chega a aplicar a regra da redução três vezes mais do que os informantes de mais idade (5,6\%). Entretanto, seria precipitado supor, aqui, uma possível mudança em progresso, pois a quantidade de dados em nossa amostra é restrita e o número de ocorrências de ambas as variantes é muito aproximado.

Na pesquisa de Martins e Bueno (2011), os resultados obtidos apontaram uma maior aplicação da redução na fala dos indivíduos com menos de 50 anos, enquanto aqueles que estavam na faixa etária acima de 50 foram os que mais preservaram a forma padrão do gerúndio. Assim, as autoras concluíram que os mais velhos tendem a conservar as formas já estabelecidas e prestigiadas. E, no trabalho de Ferreira (2010), a faixa etária foi o grupo selecionado como o mais relevante pelo programa GoldVarb X na aplicação da regra. Os resultados desse último trabalho mostraram que o fenômeno foi mais produtivo entre as faixas etárias mais jovens ( 7 a 15, de 16 a 25 e os de 26 e 35 anos) e que seu uso caía em relação às faixas etárias mais avançadas (36 a 55 e mais de 55 anos). Ou seja, tanto os resultados de nossa pesquisa quanto 
os das demais pesquisas aqui expostas, embora trabalhando com faixas etárias distintas, revelam a tendência de as faixas etárias mais jovens aplicarem com maior frequência a forma reduzida do gerúndio. Isso nos faz supor que o grupo dos mais idosos tende a ser mais conservador em relação a sua fala do que o grupo dos mais jovens.

b) Sexo

Trudgill (1974) defende que a sociedade impõe papéis distintos a homens e mulheres e espera que estes adotem padrões de comportamento também distintos. Assim, o que ocorre na linguagem seria apenas reflexo deste fato social.

\begin{tabular}{l|l|l|}
\hline \multicolumn{1}{l}{ Fatores } & \multicolumn{1}{l}{ Aplica/Total } & $\%$ \\
\hline Feminino & $7 / 49$ & 49,6 \\
\hline Masculino & $5 / 52$ & 50,4 \\
\hline
\end{tabular}

Tabela 2 - Frequências do sexo sobre a supressão da /d/ no morfema "ndo"

Os dados da tabela 2 revelam que o apagamento foi, levemente, mais produtivo entre os informantes pertencentes ao sexo masculino $(50,4 \%)$. Entretanto, a diferença da aplicação da regra entre ambos os sexos é muito pequena, o que nos faz ter cautela antes de afirmarmos que homens ou mulheres são aliados do fenômeno. No trabalho de Ferreira (2010), esta variável foi selecionada pelo programa GoldVarb X como significativa no processo de aplicação da regra variável. Em seus dados, o resultado revela que os 
homens são aliados do fenômeno, com peso relativo de 0,59, enquanto as mulheres desfavorecem a regra, apresentando peso de 0,40.

É conhecido na literatura sociolinguística que existe uma preferência do sexo feminino de se utilizar de variantes de maior prestígio social, do que as variantes estigmatizadas. Tal preferência só se concretiza quando estamos lidando com variações estáveis, ou seja, quando o indivíduo tem consciência social (changes from above) do valor da variante. Nesse caso, as mulheres usam as variantes não estigmatizadas. Já quando as mudanças não envolvem consciência social (changes from below), também são as mulheres que lideram o uso das formas inovadoras (LABOV, 2001, p.367 Apud SCHERRE; YACOVENCO, 2011, p.123). Portanto, "as mulheres se conformam mais fortemente do que os homens às normas sociolinguísticas que são explicitamente prescritas, mas se conformam menos do que os homens quando as normas não são explicitamente prescritas" (LABOV, 2001, p.293 Apud SCHERRE; YACOVENCO, 2011, p.123).

c) Área geográfica

A redução do gerúndio ocorreu com mais frequência nas cidades de Conceição de Araguaia (33,3\%) e Itaituba (36,4\%), como mostra a tabela 3. Infelizmente, em nossa análise, 
não podemos apresentar uma comparação entre nossos resultados e os dos demais trabalhos, pois os estudos que investigaram a redução do gerúndio, aqui resenhados, não incorporaram essa variável em seus respectivos trabalhos.

\begin{tabular}{|l|l|l|}
\hline \multicolumn{1}{|l}{ Fatores } & \multicolumn{1}{l}{ Aplica / Total } & $\%$ \\
\hline \multicolumn{1}{|l|}{ Itaituba } & $4 / 11$ & 36.4 \\
\hline Conceição de Araguaia & $4 / 12$ & 33.3 \\
\hline Santarém & $1 / 10$ & 10.0 \\
\hline Bragança & $1 / 11$ & 9.1 \\
\hline Altamira & $1 / 12$ & 8.3 \\
\hline Marabá & $1 / 12$ & 8.3 \\
\hline
\end{tabular}

Tabela 3 - Frequências da área geográfica sobre a supressão de /d/ no morfema /ndo/

Em busca de formular uma interpretação coerente para os achados que obtivemos em relação à variável área geográfica, procuramos saber quais eram as 10 cidades com maior índice de desenvolvimento humano (IDH) no estado do Pará, segundo dados da $\mathrm{ONU}^{4}$, e descobrimos que as duas cidades que aqui obtiveram a maior frequência na aplicação do gerúndio, não estão entre elas. O que nos faz supor que, nas cidades com maior desenvolvimento (incluindo melhor escolarização e emprego), os indivíduos procurem fazer o uso das variantes mais prestigiadas, ou seja, a forma não reduzida do gerúndio "ndo", pois nenhuma das cidades em que a redução ocorreu com maior frequência está entre as cidades com maior IDH.

4 Disponível em: http://exame.abril.com.br/brasil/noticias/as-10-cidades-mais-desenvolvidasde-cada-estado-segundo-onu. Acesso em 14.Fev.2015. 


\section{CONSIDERAÇÕES FINAIS}

No ALiSPA, constatamos que a redução do gerúndio $(10,6 \%)$ foi pouco produtiva, frente à manutenção $(89,4 \%)$ da dental no morfema "ndo", que se mostrou predominante na fala dos informantes. Os fatores sociais controlados, a saber: sexo, faixa etária e área geográfica revelaram que os homens, os mais jovens (19-33 anos) e os informantes provenientes das cidades de Itaituba e Conceição do Araguaia aplicaram mais a redução do gerúndio. Entretanto, nossos resultados devem ser relativizados, pois encontramos apenas 03 (três) itens lexicais com a terminação "ndo", que foram os verbos andando, fervendo e sorrindo, o que resultou em 113 ocorrências de verbos conjugados no gerúndio.

\section{REFERÊNCIAS}

CASTRO, Maria Lúcia Souza; BRASILEIRO, Aldecy Souza de Veras (2013). Aspectos fonéticos do falar urbano e rural de Santo Antônio de JesusBA. Revista Philologus, Vol.1, p.272-282. In http://www.filologia.org.br/ revista/55supl/022.pdf. Acesso em 16.Fev.2015.

COUTINHO, Ismael de Lima (1967). Pontos de gramática histórica. 7.ed. Rio de Janeiro: Ao Livro Técnico.

FERREIRA, Jesuelem Salvani (2010). O apagamento do /d/ em morfema de gerúndio no dialeto de São José do Rio Preto. Dissertação $142 \mathrm{f}$. (Mestrado em Estudos Linguísticos) - Universidade Estadual Paulista Júlio de Mesquita Filho, São José do Rio Preto. In http://www.bv.fapesp.br/pt/ publicacao/83692/o-apagamento-do-d-em-morfema-de-gerundio-nodialeto-de-sao-j/. Acesso em 14.Fev.2015. 
GUY, Gregory R.; ZILLES, Ana Maria Stahl (2007). Sociolinguística Quantitativa: instrumental de análise. São Paulo: Parábola Editorial. LABOV, William (1972). Sociolinguistic patterns. Philadelphia: University of Pennsylvania Press.

MARTINS, Ivone da Silva; BUENO, Elza Sabino da Silva (2011). Estudo do gerúndio - a transformação de [nd] em [n] no português falado na região de fronteira. Sociodialeto (Online), Vol.1, p.1-24. In http://www.sociodialeto. com.br/edicoes/9/28092011064716.pdf>. Acesso em 10.Fev.2015.

MOLLICA, Maria Cecília; MATTOS, Paula Barreto de (1989). Dois processos de Assimilação Fonológica no Português falado semiespontâneo do Rio de Janeiro. Mimeo.

SANKOFF, David; TAGLIAMONTE, Sali A.; SMITH, E. (2005). Goldvarb X A multivariate analysis application. Toronto: Department of Linguistics; Ottawa: Department of Mathematics. In http://individual. utoronto.ca/ tagliamonte/ Goldvarb/GV_index.htm\#ref. Acesso em: 19.Jun.2015.

SANTANA, Arthur Pereira (2012). A síncope revisitada: análise com base no corpus do ALiMA. Littera Online, Vol.5, p.50-68. In http://www. periodicoseletronicos.ufma.br/index.php/littera/article/view/1266/992. Acesso em 12.Jan.2015.

SCHERRE, Maria Marta Pereira; YACOVENCO, Lilian Coutinho (2011). A variação linguística e o papel dos fatores sociais: o gênero do falante em foco. Revista da ABRALIN, Curitiba, PR: UFPR, v. eletrônica, n. Especial, p.121-146, 1a parte. In http://ojs.c3sl.ufpr.br/ojs/index.php/abralin/ article/view/32348. Acesso em: 25.Jun.2015.

TARALLO, Fernando (2001). A pesquisa sociolinguística. 7.ed. São Paulo: Martins Fontes.

TRUDGILL, Petter (1974). Sociolinguistics. Middlesex: Penguin BooksLTD. VIEIRA, MaríliaSilva (2011). Apagamento do/d/:abordagem sociolinguística sob a perspectiva do gênero sexual. Sociodialeto (Online), Vol.1, n.4, p.1525. In http://www.sociodialeto.com.br/edicoes/9/28092011063729.pdf. Acesso em 10.Fev.2015. 
WEINREICH, Uriel; LABOV, William; HERZOG, Marvin I. (2006) [1968]. Fundamentos empíricos para uma teoria da mudança lingüística. Marcos Bagno (Trad.). São Paulo: Parábola Editorial.

Aluiza Alves de Araújo é professora Doutora do Curso de Letras e do Programa de Pós-Graduação em Linguística Aplicada da Universidade Estadual do Ceará - UECE. Cursa Pós-Doutorado na Universidade Federal do Ceará - UFC, sob a orientação da Professora Doutora Maria do Socorro Silva de Aragão. Coordena o projeto Retratos sociolinguísticos de aspectos fonológicos, morfológicos e sintáticos do falar de Fortaleza-CE. Contato: aluizazinha@hotmail.com.

Maria do Socorro Silva de Aragão é professora Doutora Visitante do Programa de Pós-Graduação em Linguística da Universidade Federal do Ceará - UFC. Professora Aposentada da Universidade Federal da Paraíba - UFPB, agora Professora Voluntária do Programa de Pós-Graduação em Letras da UFPB. Autora do Atlas Linguístico da Paraíba. Coordena o Projeto Tesouro do Léxico Galego-Português para todo o Nordeste brasileiro e é Diretora Científica do Projeto Atlas Linguístico do Brasil. Contato: socorro. aragao@terra.com.br.

Brenda Kathellen Melo de Almeida é mestranda do Programa de PósGraduação em Linguística Aplicada da Universidade Estadual do Ceará UECE e bolsista da CAPES - Coordenação de Aperfeiçoamento de Pessoal de Nível Superior. Contato: brendakathellen@yahoo.com.br. 